\title{
Evidence for post-zygotic self-incompatibility in Handroanthus impetiginosus (Bignoniaceae)
}

\author{
Nelson Sabino Bittencourt Júnior ${ }^{1}$ (D)
}

Received: 30 September 2016/ Accepted: 8 March 2017/Published online: 16 March 2017

(C) Springer-Verlag Berlin Heidelberg 2017

\begin{abstract}
Late-acting self-incompatibility (LSI) has been defined as a genetically controlled self-sterility mechanism that prevents seed set by selfing, despite normal pollen tube growth and ovule penetration in self-pollinated pistils. In species of the Bignoniaceae with LSI, such as Handroanthus impetiginosus, the selfed pistils are characterized by a marked delay in ovule penetration, fertilization, and endosperm initiation, followed by uniform pistil abscission. This highlights the contentious possibility of a post-zygotic self-incompatibility system. However, previous studies were unable to confirm fusion of the sperm and egg cell nuclei in selfed ovules. In the present study, the cytology of the embryo sac, double fertilization, and pistil longevity was investigated in $H$. impetiginosus using comparative nuclei microspectrofluorometry of DAPI-stained sections of self- vs. unpollinated pistils. Differences in both pistil longevity and ovary size between self- and unpollinated flowers at the time of pistil abscission were significant. Zygotes with double the DNA content in their nuclei relative to unfertilized egg cell nuclei were verified in selfed ovules from the first day after pollination onward, and G1 karyogamy appeared to have occurred. Our cytological analysis clearly indicates that ovules of self-pollinated pistils in $H$. impetiginosus are fertilized before pistil abscission but no embryogenesis initiation occurs, which strongly supports the idea of a post-zygotic self-incompatibility mechanism.
\end{abstract}

Nelson Sabino Bittencourt Júnior

nesbitte@ibilce.unesp.br

1 Departamento de Zoologia e Botânica, Instituto de Biociências Letras e Ciências Exatas, Universidade Estadual Paulista "Júlio de Mesquita Filho", Rua Cristóvão Colombo 2265, Jardim Nazareth, CEP 15054-000 São José do Rio Preto, São Paulo, Brazil
Keywords Late-acting self-incompatibility · Self-sterility · DNA microspectrofluorometry $\cdot$ Karyogamy ·

Fertilization $\cdot$ Female gametophyte $\cdot$ Breeding system

\section{Introduction}

Late-acting self-incompatibility (LSI) has been proposed to be a genetically controlled self-sterility mechanism that prevents the formation of seeds by self-pollination in fertile co-sexual flowering plants, despite normal phenotypic expression of pollen germination and pollen tube development in selfed pistils. This kind of incompatibility reaction differs from conventional sporophytic and gametophytic self-incompatibility (SI) systems, which characteristically present some kind of self-male gametophyte rejection at the stigmatic or stylar levels. LSI is a variable though yet poorly understood SI system that is commonly found in confamilial or congeneric species of some herbaceous and woody angiosperms, especially in the tropics (Gibbs 2014). LSI includes the following alternative situations: (1) Self-pollen tubes may grow into the ovary but do not penetrate the ovules; (2) self-pollen tubes may penetrate ovules but stop within the micropyle or nucellus; (3) ovules may be penetrated, but syngamy fails to occur following discharge of the male gametes into the embryo sac; and (4) self-fertilization may occur, but embryogenesis does not follow (see review in Seavey and Bawa 1986).

However, self-sterility is likely to have diverse causes, and early-acting inbreeding depression (EID) due to the expression of deleterious recessive alleles may also result in normal pollen tube growth, effective ovule penetration/ fertilization, and null or almost null seed set by selfing (Burbidge and James 1991; Sage et al. 1994; Valtueña et al. 
2010). In long-lived trees, it is difficult if not impossible to achieve a rigorous demonstration of a genetic system that controls SI due to difficulties with establishing sibling progeny arrays and raising them to flowering so that diallel crosses can be made (Gibbs 2014). Although self-fertilization without embryogenesis (the abovementioned situation 4) may imply some kind of "post-zygotic" SI mechanism of pistil rejection, conventional SI mechanisms are all pre-zygotic in action, and embryo/early seed failure has been traditionally explained by EID (Wiens et al. 1987, Klekowski 1988).

Several cases of LSI have been reported in the family Bignoniaceae (Bittencourt et al. 2003, 2011; Bittencourt and Semir 2004, 2005, 2006; Gandolphi and Bittencourt 2010; Gibbs and Bianchi 1999), a predominantly neotropical family with important species in Central and South American forests (Olmstead et al. 2009). Around 84\% of the 62 Bignoniaceae species investigated for breeding systems are self-sterile (e.g., Bittencourt et al. 2011; Sampaio et al. 2016). Among these, the post-pollination events have been studied for 37 species, all of which show self-pollen tube growth to the ovary and penetration of most ovules. Double fertilization presumably occurs because penetrated ovules show a resting zygote (or an initiating proembryonal tube) and the early phases of endosperm development at successive time points after self-pollination (Bittencourt et al. 2003, 2011; Bittencourt and Semir 2005; Gandolphi and Bittencourt 2010). However, selfed pistils/young fruits uniformly abort a few days after pollination, and only crossed fruits reach maturity. In these studies, indirect evidence of self-fertilization has been achieved through observations on the egg apparatus features/pattern of staining after the embryo sac penetration by the pollen tube.

At least in some cases, post-pollination development of ovules is evinced by extended longevity of, but only moderate increase in ovary size in selfed pistils relative to unpollinated pistils, and a slower rate of endosperm development in their ovules compared to cross-pollinated pistils, but with no sign of endosperm or early proembryonal tube malformation (Bittencourt et al. 2011; Gandolphi and Bittencourt 2010). This sequence of events strongly supports the idea of post-zygotic LSI in self-sterile species of Bignoniaceae.

As in other angiosperms, fusion of male and female gametes is very difficult to observe employing conventional microscopy observations of ovule sections in Bignoniaceae. This difficulty results from methodological limitations - the megagametophyte is usually embedded in several layers of nucellar/integumentary cells of the ovule, which hinders observation of the fertilization-related events in histological sections or even in cleared whole ovules. Conversion of the egg cell into a zygote has been inferred from the presence of a cytoplasmic loop of a deeply stained degenerative synergid between the egg cell and the central cell after pollen tube content has been discharged into the embryo sac (Bittencourt et al. 2003; Bittencourt and Semir 2005). Moreover, there is further evidence for a putatively fertilized egg cell in the reconstitution of the cell wall around the chalazal pole of the egg cell, since the egg apparatus cells lose part of their walls during the late stages of embryo sac maturation (Bittencourt and Semir 2005; Bittencourt and Moraes 2010). The dissolution of the common walls between an egg cell, synergids, and a central cell during the maturation of the embryo sac seems to be a normal phenomenon in angiosperms because it facilitates the transference of sperm cells from the degenerative penetrated synergid to the egg and central cells, and the zygote wall is re-synthesized after gamete fusion (Natesh and Rau 1984; Willemse and van Went 1984; van Went and Willemse 1984). However, in the Bignoniaceae, reconstitution of the cell wall at the chalazal pole of the egg cell has also occasionally been observed in unfertilized megagametophytes of unpollinated pistils collected at the end of anthesis (personal observations). Furthermore, since pseudogamic development of the endosperm in Bignoniaceae is possible (Bittencourt and Semir 2005; Bittencourt and Moraes 2010; Sampaio et al. 2013), and embryogenesis may conceivably occur parthenogenetically (Batygina and Vinogradova 2007), these morphological features of post-penetration events cannot be taken as unequivocal evidence of syngamy and zygote formation in selfed ovules of self-sterile species. Establishing that syngamy occurs is pivotal for the concepts of "post-zygotic" SI and EID because conventional homomorphic SI is reputed to act before fertilization, and homozygosity is a prerequisite for recessive lethal gene expression in developing embryos (Sage et al. 1994). However, no previous study has attempted to look at syngamy in a LSI species with observations of DNA content in egg cells/putative zygote cells.

For successful fertilization, the cell cycles of the sperm cell and egg cell need to be synchronized, and karyogamy in flowering plants may occur in the $\mathrm{G}_{1}, \mathrm{~S}$, or $\mathrm{G}_{2}$ phases of the cell cycle-i.e., with $1 \mathrm{C}$, intermediate, or $2 \mathrm{C}$ gamete complement of genomic DNA, respectively, depending on the taxon (Batygina and Vasilyeva 2001; Friedman 1999; Mogensen and Holm 1995; Tian et al. 2005). Very few studies have focused on the type of karyogamy in seed plants (Carmichael and Friedman 1995; Friedman 1991; Mogensen et al. 1995; Mogensen and Holm 1995; Tian et al. 2005; Woodard 1956), and none have investigated bignoniaceous taxa. These studies measured DNA content in the sperm cell, egg cell, zygote, or other male and female gametophyte nuclei through microphotometric analysis of sections subjected to the Feulgen technique or, more 
recently, through microspectrofluorometric analysis of sections stained with 4',6-diamidino-2-phenylindole dihydrochloride (DAPI), a DNA-binding fluorochrome. This study uses the DAPI staining technique for DNA quantification of the embryo sac nuclei in self-pollinated pistils of Handroanthus impetiginosus with the aim of confirming gamete fusion and egg cell-zygote conversion.

\section{Materials and methods}

\section{Species and study site}

Field work was conducted from 2006 to 2008 with planted trees at the Universidade Estadual Paulista "Júlio de Mesquita Filho" (lat. $20^{\circ} 47^{\prime} 05^{\prime \prime} \mathrm{S}$, long. $49^{\circ} 21^{\prime} 36^{\prime \prime} \mathrm{W}$, municipality of São José do Rio Preto, São Paulo, Brazil). Handroanthus impetiginosus (Mart. ex DC.) Mattos is a 2to 30-m-tall tree distributed from Northwest Mexico to Northwest Argentina, mostly in seasonally dry, deciduous, or semideciduous forests (Gentry 1992). It is one of the main species of "ipês" used in Brazil for urban afforestation and is highly appreciated for its mass flowering during the dry season (Schlindwein et al. 2014). At this time, its foliage falls and the branches can display thousands of showy tubular-campanulate magenta flowers. It is also an economically important tree for its hard and durable wood. A voucher was deposited in the São José do Rio Preto Herbarium (29217).

\section{Experimental pollinations}

Previous studies examined the breeding system based on controlled experimental pollinations in $H$. impetiginosus and found self-sterility (Bittencourt and Semir 2005). To confirm self-sterility in the study population, hand pollination was conducted on four trees. Whole inflorescences with flower buds were bagged with nylon netting, and on the subsequent days, flowers of first-day anthesis were selfpollinated (with pollen from the same flower or another flower of the same individual) or cross-pollinated (with pollen from another individual) and re-bagged. From each individual, 25 flowers were treated in each pollination type, and the resulting fruits were monitored until pistil abscission or fruit maturation.

\section{Ovary growth and longevity}

Additional hand self-pollinations were done on the same individuals to evaluate ovary expansion and longevity and for collection. Flowers of first-day anthesis from previously bagged inflorescences were self-pollinated $(n=$ at least 3 flowers per individual), and other flowers of the same inflorescences were left unpollinated and used as control. The calyx of each flower was marked with different colors of plastic glue to indicate a particular treatment (i.e., selfed or unpollinated) and the day of anthesis initiation. After manipulation, the inflorescence was re-bagged, and pistils were monitored daily until abscission. The maximal length and width of abscised ovaries were measured with a digital caliper before wilting.

\section{Histological analysis of ovules and microspectrofluorometry}

Unpollinated pistils were collected from first-day and fourth- to fifth-day flowers (early and late anthesis, respectively), and selfed pistils were collected from the second, third, and fourth days of anthesis (1-3 days after pollination). Pistil wall was removed to expose ovules adhering to the septum and was fixed for $24 \mathrm{~h}$ in a $3: 1$ solution of $95 \%$ ethanol/acetic acid and stored in $70 \%$ ethanol. After complete dehydration in an ethanol series, the samples were embedded in Leica historesin (glycolmethacrylate) and sectioned in serial 6- $\mu$ m-thick sections with glass knives in a Leica RM 2255 rotary microtome (Leica, Wetzlar, Germany).

The sections were mounted on glass slides and subjected to DAPI staining procedures following Williams and Friedman (2002). The sections were stained with a solution of $0.25 \mu \mathrm{l} / \mathrm{ml}$ of DAPI in $0.05 \mathrm{M}$ Tris ( $\mathrm{pH} 7.2$ ) for $1 \mathrm{~h}$ at room temperature in a light-free environment. Next, most part of the DAPI solution was removed from the slide, and a coverslip was applied over the sections and sealed with colorless nail polish. Microspectrofluorometric measurements of relative DNA levels of DAPI-stained nuclei were taken within $2 \mathrm{~h}$ in a Zeiss MSP 20 microspectrophotometer with digital microprocessor coupled to a Zeiss Axioskop microscope (Carl Zeiss, Jena, Germany) and equipped with epifluorescence (HBO100-W burner). An ultraviolet filter set (model number 48702) with an excitation filter (365 nm, bandpass $12 \mathrm{~nm}$ ), dichroic mirror (FT395), and barrier filter (LP397) was used with a Zeiss Plan Neofluar 40X objective. The photometer was standardized by recording the fluorescence emitted from a fluorescence standard (GG 17) before each recording session, which was taken to represent 100 relative fluorescence units (RFU). At the completion of each session, an additional reading of the fluorescence standard was taken to confirm that little or no deviation had occurred during the period of data recording.

When the entire nucleus was not embedded in the same section, its relative DNA content was determined by summing the individual fluorescence values of each of the serial sections through that nucleus. A net photometric value for each section of a nucleus was obtained by 
recording an initial reading of the nucleus and subtracting a background value obtained from cytoplasm proximal to that nucleus. Thus, background fluorescence from the glycol-methacrylate was removed from the photometric analysis of relative DNA content. Digital micrographs were taken on the same Zeiss Axiophot microscope (Carl Zeiss, Jena, Germany) equipped with a Zeiss Axiocam digital camera.

To complement the structural analysis of the ovules, after all microspectrofluorometric measurements, the coverslip was removed from each slide, and the sections were stained with toluidine blue O (O'Brien et al. 1964) and sealed with Permount. Additional selfed pistils were collected on the fifth and sixth days after anthesis initiation (4-5 days after pollination), fixed, and sectioned as before and stained with toluidine blue. Analysis and photographic records of toluidine blue-stained sections were made with an Olympus BX51 microscope (Olympus Optical, Tokyo, Japan) equipped with an Olympus Q-Color 5 digital camera.

\section{Statistical analysis}

The homoscedasticity and normality of pistil longevity, ovary size, and fluorescence of zygote nuclei data were tested by the $F$ - and Kolmogorov-Smirnov (Lilliefors adherence) tests. Because the longevity in both self-pollinated and unpollinated pistils did not have normal distributions, they were statistically compared using the MannWhitney test (Zar 1999). The Student's $t$-test was used to compare the ovary sizes (length and width) of abscised unpollinated versus selfed pistils. In order to determine whether mean relative fluorescences of zygote nuclei at successive days after pollination were statistically greater than in a previous day, a series of $t$-tests was also performed with the data of zygote nuclei fluorescence measurements. Statistical analysis was done using BioEstat 2.0 software (Ayres et al. 2000).

\section{Results}

Independently of the treatment, corolla abscission and fall (end of anthesis) always occurred between the third and the fifth days after the flower opening. Only hand cross-pollinated flowers set fruits, which required around three months to mature. Both the longevity and ovary size at abscission in self-pollinated pistils were greater than in unpollinated pistils (Fig. 1).

Handroanthus impetiginosus has an anatropous (Fig. 2i), unitegmic, and tenuinucellate ovule with a Polygonum-type megagametophyte (Fig. 2a-g), which is common for all Bignoniaceae. Most ovules in first-day unpollinated pistils displayed mature seven-celled eightnucleate embryo sacs, with two synergids and an egg cell composing a hooked egg apparatus at the micropylar end, a central cell with two polar nuclei, and three antipodals at the chalazal end (Fig. 2a, b). However, the ovaries of these pistils also showed many ovules with immature coenocytic 2-8 nucleate embryo sacs or embryo sacs that were already cellularized but still showing an unexpanded egg apparatus, as reported elsewhere (Bittencourt and Semir 2005).

Unfortunately, mitotic figures were never observed in these cenocytic phases of the embryo sac, so it was not possible to directly calibrate the relative fluorescence per $\mathrm{C}$ unit of DNA. However, the nuclei of a syncytial megagametophyte are haploid and vary in DNA content by a factor of two over the course of the cell cycle (1C during anaphase, telophase, and $\mathrm{G}_{1}$ phase; between $1 \mathrm{C}$ and $2 \mathrm{C}$ during the $\mathrm{S}$ phase; and $2 \mathrm{C}$ during $\mathrm{G}_{2}$, prophase and metaphase). Moreover, after cellularization of the embryo sac, antipodals and synergids were never observed to undergo further mitosis or cell division. Thus, they are presumed to remain permanently in a $G_{1}$ phase of the cell cycle (i.e., showing $1 \mathrm{C}$ content of genomic DNA).

Despite the examination of hundreds of megagametophytes with fluorescence microscopy, only two 8-nucleate uncellularized embryo sacs were found (this phase seems to be very ephemeral), and measurements of their nuclei yielded $7.23 \pm 0.82 \mathrm{RFU}$ (mean \pm standard deviation) per nucleus ( $n=11$; the other nuclei were not measurable). Likewise, measurements of nuclei of the embryo sac at the onset of the receptive phase (i.e., the synergids, egg cells, polar nuclei, and antipodals in mature ovules of first-day anthesis unpollinated pistils) yielded 7.01 \pm 1.14 RFU $(n=32)$ (Fig. 3a). At this stage, the nuclei of these megagametophytes are in the onset of the mature phase and have just emerged from the last mitotic round of the megagametogenesis, which means they should be in $G_{1}$ of the cell cycle and thus approximately equivalent to the amount of fluorescence associated with the $1 \mathrm{C}$ content of DNA.

As in other Bignoniaceae, the cell components of the egg apparatus in $H$. impetiginosus typically display elongate pear-shaped synergids and an egg cell. The synergids show the nucleus and most of the cytosol at the micropylar pole, with a large vacuole at the chalazal pole of the cell. The egg cell shows an inverted polarity relative to the synergids, with the nucleus and most of the cytosol at the chalazal pole and a large vacuole at the micropylar pole (Fig. 2a-g). Thus, the synergid and egg cell nuclei were easily distinguished in sectioned material due to their relative position in these cells.

Egg apparatus cells in the early mature embryo sac characteristically did not show a detectable cell wall at the chalazal end. Some ovules with the embryo sac bearing a 

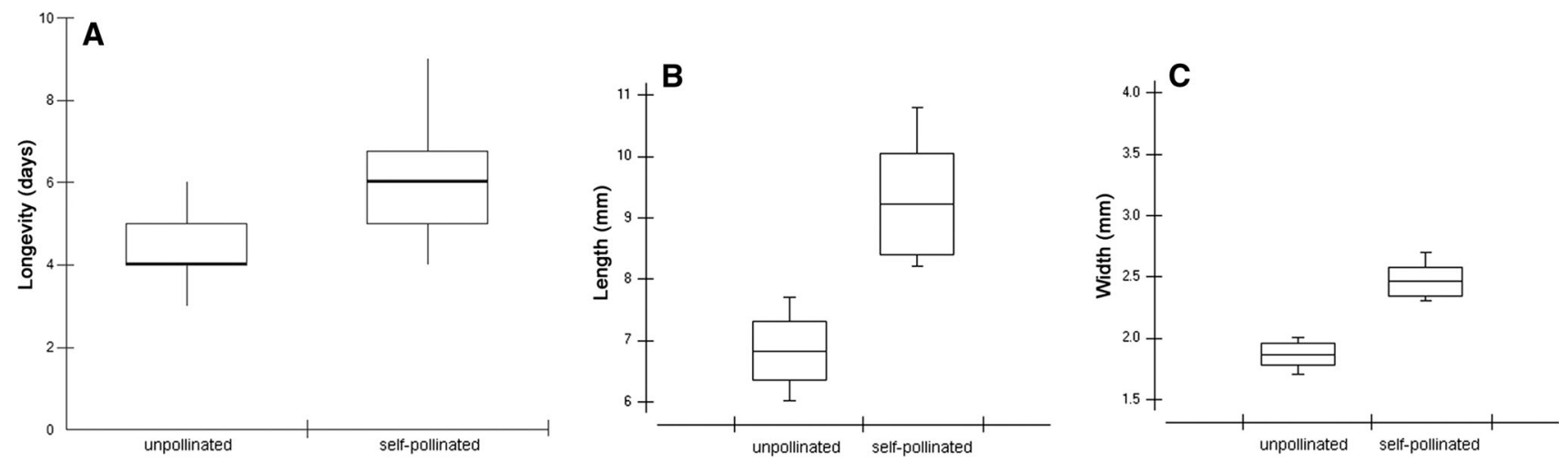

Fig. 1 Pistil longevity (a) and ovary size at abscission (b, c) in unpollinated and self-pollinated flowers of Handroanthus impetiginosus. Boxes represent the lower quartile, median, and upper quartile (a) or average and standard deviation $(\mathbf{b}, \mathbf{c})$. Error bars represent the variation between minimum and maximum values. Mann-Whitney

secondary nucleus (the product of polar nuclei fusion) in the central cell were found in first-day anthesis ovaries of unpollinated pistils, and fluorescence measurement yielded approximately doubles the values observed in unfused polar nuclei and nuclei from other cells of the early mature megagametophyte (Fig. 4a). Only secondary nucleusbearing embryo sacs were observed in ovaries at late anthesis (Fig. 4b). These results indicate that polar nuclei fusion in $H$. impetiginosus may operate independently of fertilization or any stimulus of the male gametophyte. Measurements of antipodal nuclei in both unpollinated and self-pollinated pistils always gave lower RFU values (Figs. 4 and 5), which may be related to degeneration associated with the ephemeral condition of these cells.

Several ovules showing a pollen tube into the micropyle were observed in sections of ovaries of the first day after self-pollination (second-day anthesis). After full penetration of a receptive ovule, the pollen tube discharged its dense and dark toluidine blue-staining contents into the degenerating synergid, which made distinguishing the contents of this cell difficult. Subsequently, a protoplasmic loop of the degenerating synergid was always observed between the chalazal end of the egg cell and the central cell (Fig. 2d, f). In our previous studies, this was assumed to be related to the transference of the sperm cell nuclei from the degenerating synergid to the egg and central cell.

Sperm cells were rarely verified in penetrated gametophytes, and we were unable to make detailed observations of the events involving the discharge and movement of the male gametes into the embryo sac in neither toluidine bluestained nor DAPI-stained sections. However, fluorescence measurements from two sperm nuclei located inside the penetrated synergid and from one sperm nucleus inside the egg cell (next to its nucleus; Fig. 2h) yielded 6.54, 6.71, and $7.58 \mathrm{RFU}$, respectively. Direct observations of the test indicated significant difference between longevity of unpollinated and self-pollinated pistils $(P=0.0038)$. Student's $t$-test indicated significant difference between unpollinated and self-pollinated pistils in ovary length $(t=8.69, P<0.001)$ and width $t=13.99$, $P<0.001)$

fusion of gamete nuclei were also only made on a few occasions (Fig. $2 \mathrm{~g}$ for triple fusion and Fig. $2 \mathrm{~h}$ for syngamy). The first division of the primary endosperm (observed from the second day after pollination onward) was always transverse and followed the zygote formation, resulting in the characteristic chalazal and micropylar chambers of the 2-celled phase of the endosperm (Figs. 2i and 3a) which is characteristic of the Bignoniaceae. Regeneration of a pink-purple toluidine blue-staining wall was observed between the zygote and primary endosperm cell or between the zygote and the micropylar chamber of the 2-celled endosperm (Fig. 3a). Fluorescence measurements of zygote nuclei on the first day post-pollination yielded $14.01 \pm 1.16 \mathrm{RFU}$ ( $n=9$; Fig. 5a), which is nearly double the average values obtained for egg cell nuclei in ovules of unpollinated and self-pollinated pistils (Figs. 4 and 5).

As in unpollinated pistils, unfertilized ovules of selfed pistils on the first and second days after pollination showed a pair of unfused polar nuclei or a single-secondary nucleus in the central cell, which approached $1 \mathrm{C}$ and 2C DNA content per nucleus, respectively (Fig. 5a, b). However, on the third day after pollination (fourth-day anthesis), unpenetrated ovules in selfed pistils rarely showed unfused polar nuclei. On the other hand, fertilized ovules on the second and third days after pollination exhibited a primary endosperm nucleus (the product of polar nuclei/secondary nucleus and sperm cell nucleus fusion), with measurements yielding approximately three times more DNA $[23.63 \pm 2.57 \mathrm{RFU}$ (mean \pm standard deviation; second + third days, $n=15$ ); Fig. 5b, c] than polar nuclei or other haploid nuclei of the female gametophyte. This corresponds to the expected 3C units of DNA content (based on the basic haploid level observed). However, the two highest values (26.50 and 26.83 RFU) observed in primary endosperm cell nuclei are 

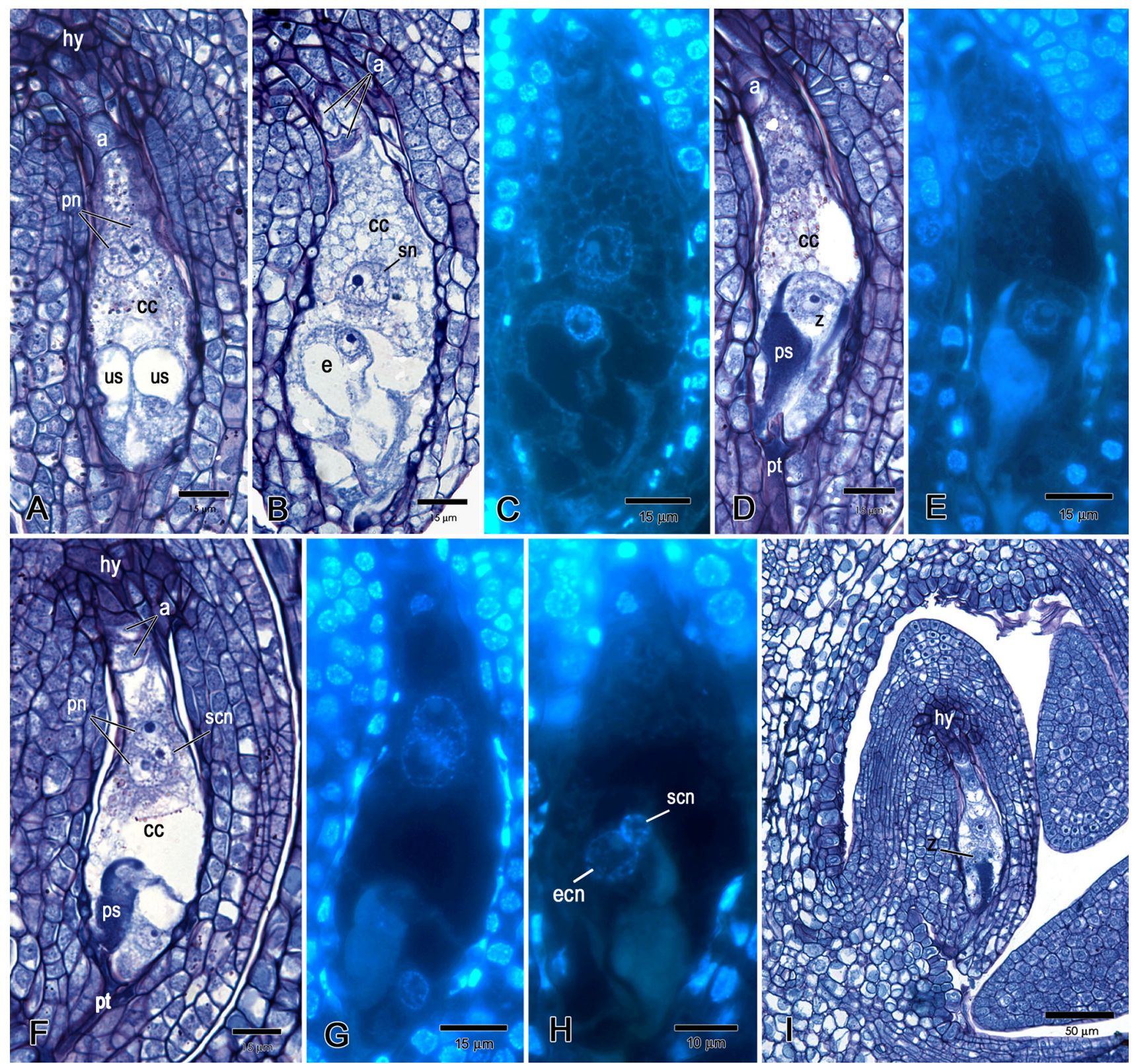

Fig. 2 Light and epifluorescence microscopy of longitudinal sections of ovules in Handroanthus impetiginosus. a-c Unpollinated pistils. Embryo sacs on the second-day anthesis. d-g: Penetrated embryo sac in self-pollinated pistils on third-day anthesis showing fusing polar nuclei (d, e), triple fusion (f, $\mathbf{g})$, and syngamy (h). General aspect of a selfed ovule showing an initiating endosperm at the 2-celled stage (I).

equivalent to a DNA complement level of 3.8. This is probably a consequence of the fact that some of these nuclei have progressed to the $\mathrm{S}$ phase that precedes mitosis since the first division of endospermogenesis appeared to occur quickly after triple fusion.

After the first cytokinesis of the endosperm development, both the micropylar and chalazal cells of the 2-celled endosperm divide longitudinally and simultaneously, giving four cells. Alternatively, the micropylar cell of the

Staining: toluidine blue O (a, b, d, f, i), 4',6-diamidino-2-phenylindole $(\mathbf{c}, \mathbf{e}, \mathbf{g}, \mathbf{h}) . a$ antipodals, $c c$ central cell, $e$ egg cell, ecn egg cell nucleus, hy hypostase, pn polar nuclei, ps penetrated synergid, $s c n$ sperm cell nucleus, $s n$ secondary nucleus, $u s$ unpenetrated synergid, $p t$ pollen tube, $z$ zygote

2-celled endosperm may divide longitudinally to give two cells (3-celled endosperm), and the third mitotic cycle is signaled by a longitudinal division of the chalazal cell (4celled endosperm). Subsequently, the micropylar cells each divide transversely into two intermediate or central cells (6-celled endosperm). Thereafter, early endosperm development proceeds conventionally by waves of synchronized divisions of the central cells only, giving two longitudinal rows of endosperm cells (Fig. 3b). 


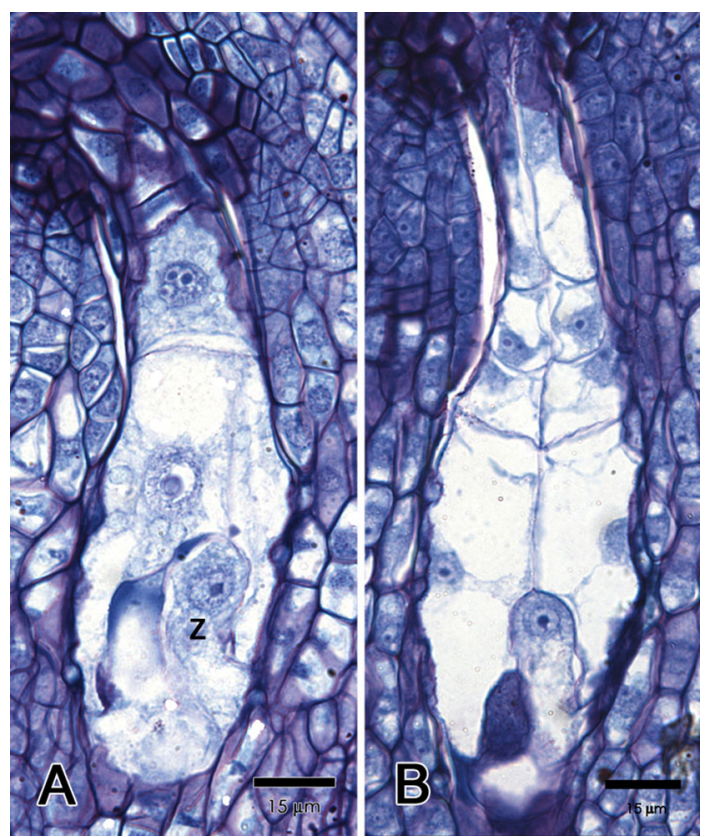

Fig. 3 Light microscopy of longitudinal sections of fertilized ovules in Handroanthus impetiginosus. a Two-celled endosperm on the second day after self-pollination. b Eight-celled endosperm on the fifth day after self-pollination. Staining: toluidine blue O. hy hypostase, $z$ zygote
The zygote nucleus remained unmodified (in the interphase of the cell cycle) at the chalazal end of the cell and showed a conspicuous nucleolus up to the most advanced stage of ovule development observed, but the cell started to elongate (Fig. 3b). Measurements of zygote nuclei in the ovules of selfed pistils on the second and third days after pollination resulted in $14.41 \pm 1.78$ and $14.78 \pm 1.92$ RFU (mean \pm standard deviation, $n=19$ and 16), respectively (Fig. 5b, c), which also approach 2C DNA content. Student's $t$-test did not indicate a significant difference of RFU in zygote nuclei between pistils of the first, second, and third days after pollination. However, one of the zygote nuclei on the second day yielded 18.05 RFU, and three nuclei on the third day yielded values of 17.50 , 18.04, and 18.75 RFU (Fig. 6a-c), which correspond approximately to $2.5-2.7$ units of DNA. These higher values caused an asymmetry in the data dispersion around the mean on the third day after pollination (Fig. 7) and seem to indicate that at least in some ovules of selfed pistils the zygote may have progressed from the $G_{1}$ to the $S$ phase of the cell cycle on the second and third days after pollination.
Fig. 4 Averages of relative DNA content in embryo sac nuclei of unpollinated flowers on the first (a) and third-fourth (b) days of anthesis. Error bars indicate standard deviations. The number of measured nuclei in each category is shown at the center of each column. $X$-axis titles mean synergid, egg cell, polar nucleus, antipodal and secondary nucleus, respectively. Seven $\mathrm{RFU} \approx 1 \mathrm{C}$ DNA
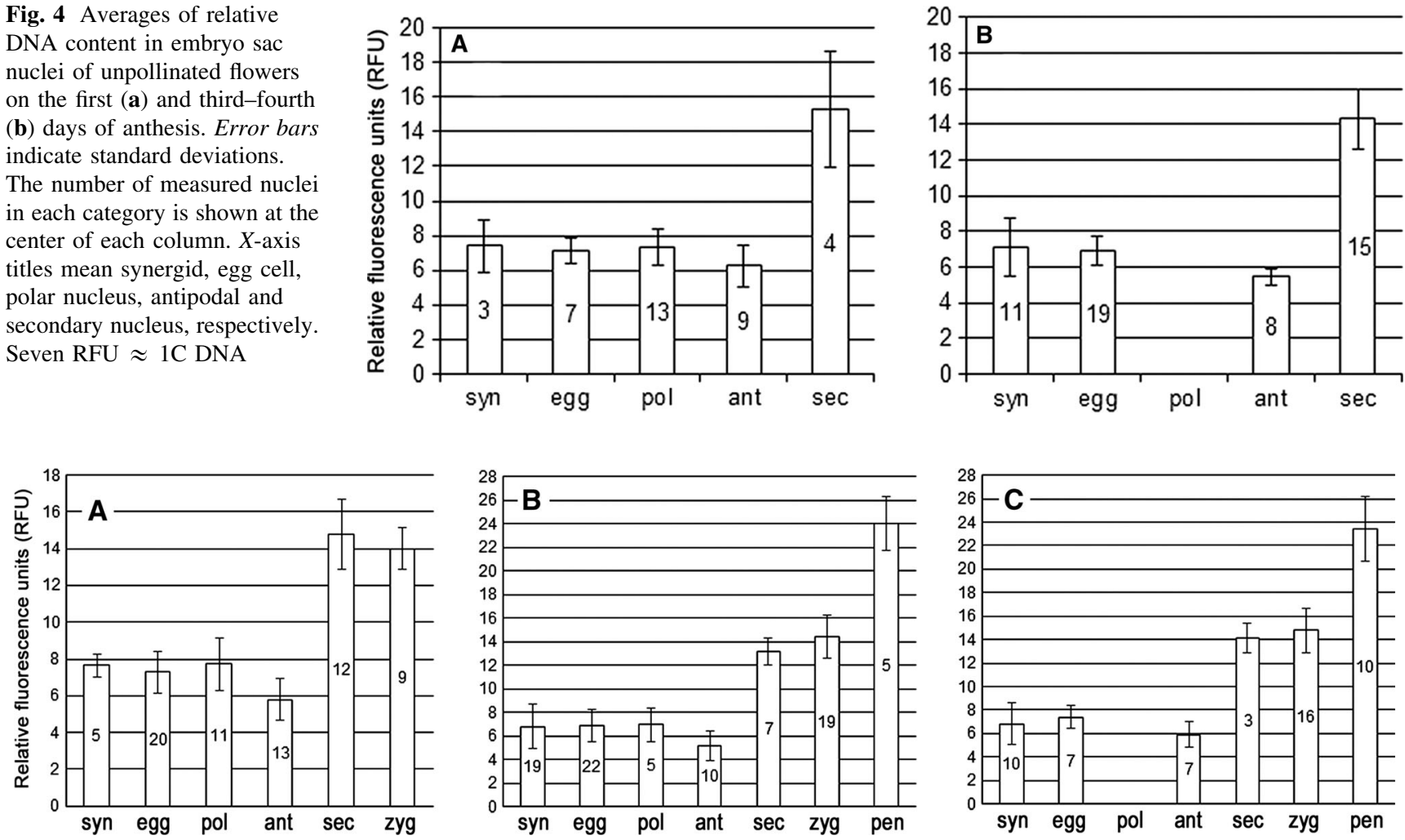

Fig. 5 Averages of relative DNA content in embryo sac nuclei of self-pollinated flowers on the second (a), third (b), and (c) fourth days of anthesis. Error bars indicate standard deviations. The number of measured nuclei in each category is shown at the center of each column. $X$-axis titles mean synergid, egg cell, polar nucleus, antipodal and secondary nucleus, zygote and primary endosperm nucleus, respectively. Seven RFU $\approx 1 \mathrm{C}$ DNA 

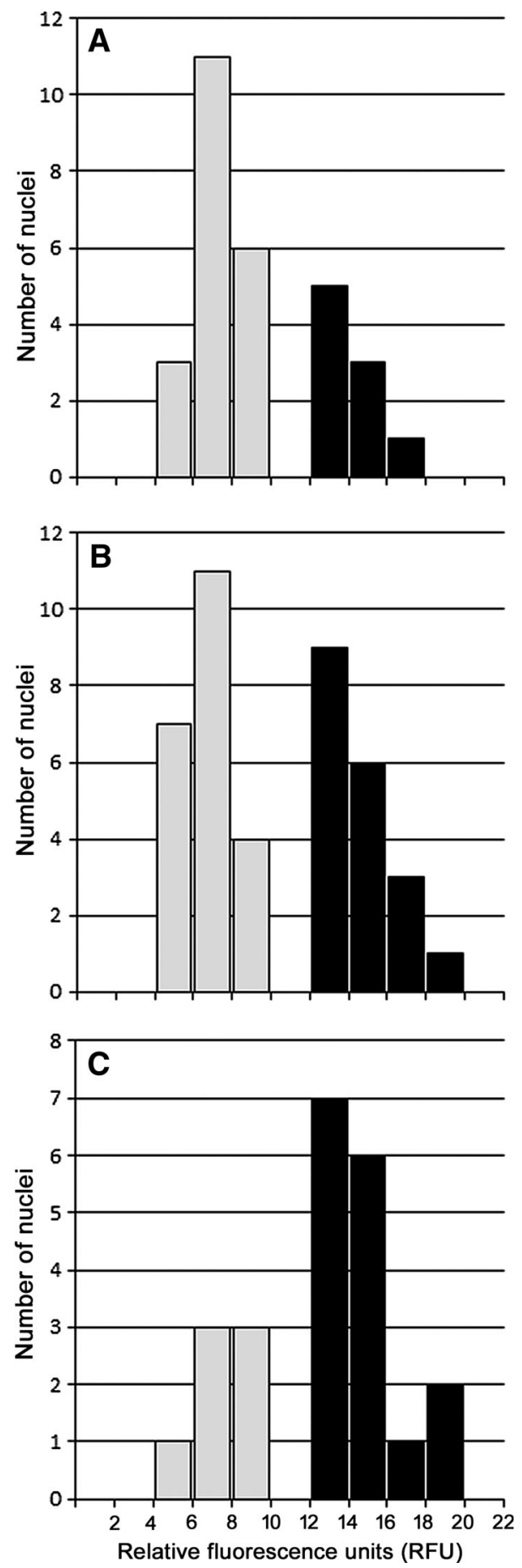

Fig. 6 Relative DNA fluorescence of putative egg cells and zygotes as estimated by the presence or absence (in the egg apparatus) of a dark staining penetrated synergid showing a cytoplasmic loop at its chalazal end. On the first (a), second (b), and third (c) days after selfpollination. Seven and 14 RFU approach 1 and 2C DNA content, respectively

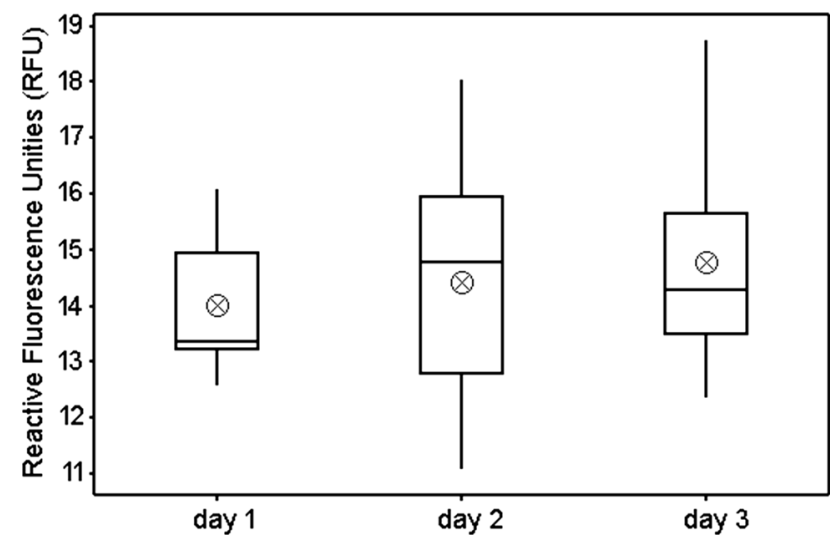

Fig. 7 Relative DNA fluorescence of zygotes on the first, second, and third days after self-pollination. Boxes represent the lower quartile, median, and upper quartile. Circled times symbols indicate means. Error bars represent the variation between minimum and maximum values. Student's $t$-tests did not indicate significant differences between the first and third days

\section{Discussion}

The results demonstrate that except for the secondary nucleus, all nuclei of the female gametophyte (including the egg cell nucleus) remain in a haploid 1C level of DNA unless pollen tube penetration and male gamete delivery into the embryo sac occur. Even on the last day of anthesis, the egg cell in ovules of unpollinated flowers showed no variation from this 1C DNA content. Measurements of sperm cell nuclei delivered into the embryo sac by the pollen tube also yielded a 1C level of DNA, whereas egg apparatus cells histologically recognized as zygotes in most ovules of self-pollinated pistils presented a diploid $2 \mathrm{C}$ level of DNA, indicating that syngamy occurred in these ovules. As expected, the central cell presented 1 or $2 \mathrm{C}$ chromosome levels in polar nuclei and the secondary nucleus, respectively, and a $3 \mathrm{C}$ level after the fusion with another sperm cell nucleus in selfed ovules. These results unequivocally indicate that double fertilization occurs in selfed ovules of $H$. impetiginosus.

The results also show that $\mathrm{G}_{1}$ karyogamy appears to occur in $H$. impetiginosus. Although differences in RFU measurements between zygote nuclei from pistils of 1-3 days after pollination were not significant, a tendency for an excess of DNA (relative to the $2 \mathrm{C}$ level) in third-day selfed zygote nuclei was indicated by its asymmetric data dispersion due to a few measurements approaching the 2.7 level of DNA. Therefore, selfed ovules presented zygotes with DNA levels apparently higher than $2 \mathrm{C}$ on only the second and third days after pollination, indicating that the $\mathrm{S}$ 
phase of the cell cycle initiates after the gamete fusion. Despite the paucity of studies dealing with the type of karyogamy in plants, $G_{1}$ gamete fusion is probably the most common (Gerassimova-Navashina 1960; Raghavan 2003) and has been correlated with most bicellular pollenproducing angiosperms (Friedman 1999; Tian et al. 2005), which is a condition found in the majority of the Bignoniaceae (Davis 1966; Johri et al. 1992b; Konyar 2014).

The features used in our previous studies on post-pollination events in self-sterile species of the Bignoniaceae to recognize an ovule as fertilized-i.e., the presence of a toluidine blue dark-staining penetrated synergid showing a cytoplasmic loop, and regeneration of the cell wall around the chalazal end of the egg cell/zygote (Bittencourt et al. 2011, 2003; Bittencourt and Semir 2005; Gandolphi and Bittencourt 2010)—were also verified in the present study, where DAPI identification of nuclear DNA content provided conclusive evidence of syngamy. In effect, the assumption that the cytological features seen in previous studies were truly indicative of the occurrence of fertilization was correct. Furthermore, all the functional ovules in the study of Bittencourt and Semir (2005) showed the same indirect fertilization-signaling features up to $120 \mathrm{~h}$ after self-pollination, meaning that most (if not all) selfed ovules in $H$. impetiginosus were fertilized. Therefore, rejection of self-pollinated pistils in $H$. impetiginosus is clearly post-zygotic.

As in other populations of this species (Bittencourt and Semir 2005; Bullock 1985; Milet-Pinheiro et al. 2009; Schlindwein et al. 2014; Stevens 1994), only cross-pollinations resulted in fruit set (in the present study there was no fruit set from 100 self-pollinated flowers in four trees), which indicates strong self-sterility and confirms that $H$. impetiginosus is a xenogamous species. The longevity of selfed pistils was longer than in unpollinated pistils, and the greater size of selfed ovaries at abscission clearly shows that some ovary expansion seems to be induced by self-pollination, although the signal to suppress pistil abscission that occurs in crossed pistils, and which must occur during a short period after anthesis, is obviously lacking in selfed pistils.

The extended longevity of selfed pistils (i.e., the delay observed in their abscission) may arise from some kind of self-pollen tube/pistil interaction. This delay in selfed pistil abscission has been also observed in other LSI species (Bittencourt et al. 2011; Gandolphi and Bittencourt 2010; Gibbs et al. 2004). It is presumed to result from some form of interaction or "cross talk" (between pollen tubes growing in the transmitting tract and the ovules in the ovary) that may operate in the mode of action of a SI system. Despite the delay, selfed pistil longevity corresponds to less than $7 \%$ of the time a fruit needs to complete its development compared to the time spent by fruits derived from cross-pollination (none of the selfed pistils in this study persisted on the trees for more than nine days after anthesis initiation). This may also indicate an underlying SI system associated with the self-sterility of $H$. impetiginosus because selfed pistil abortion in a continuum of developmental stages should be expected in an EID context (Hao et al. 2012; Sage et al. 1994; Seavey and Bawa 1986; Valtueña et al. 2010), despite the possibility of an increasing shortage of this continuum due to selection of early-acting recessive lethals in selfed ovules to minimize maternal investment in doomed embryos/seeds (Burbidge and James 1991).

LSI, as manifested in Bignoniaceae and many other taxa, differs from mechanisms observed in species that show conventional sporophytic (homomorphic and heteromorphic) and gametophytic SI in having a post-zygotic rather than pre-zygotic rejection. Despite this difference, a number of studies have sought to determine whether LSI has a similar genetic (major gene) control to those found in homomorphic SI. Nonetheless, this genetic control was determined in very few LSI species (Cope 1962; LaDoux and Friar 2006; Lipow and Wyatt 2000). Because the LSI mechanism is not yet fully understood, some researchers prefer to use other designations, such as pistillate sorting (Bertin et al. 1989) or ovarian sterility (Sage et al. 1994), implicating no presumptions about the control mechanisms (i.e., maternal, paternal, zygotic, or some combination of these).

As mentioned, because there is a tendency for inbreeding depression (fitness loss) to be particularly intense between fertilization and the mature seed phase (Husband and Schemske 1996; Meinke 1991; Seavey and Carter 1994), EID can be an alternative explanation to the selfsterility syndrome associated with LSI. However, as in our previous study in H. impetiginosus (Bittencourt and Semir 2005), no sign of endosperm malfunctioning (that would trigger pistil rejection) was observed in the very narrow window of time between the effective endospermogenesis initiation (almost a half of the ovules have not reached the two-celled phase of the endosperm development up to the fourth day after self-pollination) and complete abscission of selfed pistils (up to nine days). Moreover, as observed in the present study, the initial steps of endosperm development in the Bignoniaceae occur before the first division in the zygote (Bittencourt et al. 2003, 2011; Bittencourt and Morais 2010; Bittencourt and Semir 2005; Costa et al. 2004; Gandolphi and Bittencourt 2010; Gibbs and Bianchi 1999; Govindu 1950; Sampaio et al. 2013; Shivaramiah 1998). As in many sympetalous families like Schrophulariaceae, Acanthaceae, Gesneriaceae, and several others (Johri et al. 1992a, b), the zygote in species of the Bignoniaceae assumes a tube-like structure and elongates considerably toward the chalazal pole of a biseriate 
expanding endosperm before the first cytokinesis. This initial elongation of the zygote may be accompanied by nuclear division to form a binucleate proembryonal tube (Bittencourt et al. 2003; Bittencourt and Semir 2005; Gandolphi and Bittencourt 2010), but cell division (cytokinesis) to produce the two-celled proembryo (exclusively derived from the chalazal nucleus of the proembryonal tube) occurs only after the chalazal portion of the endosperm has become multilayered (five days after cross-pollination in Tabebuia roseoalba; Gandolphi and Bittencourt 2010). In H. impetiginosus, a two-nucleate proembryonal tube was observed in ovules of selfed pistils on the sixth or seventh day after pollination (Bittencourt and Semir 2005). As in other self-sterile species of Bignoniaceae, a two-celled proembryo was never observed in ovules of selfed pistils because they abscise before reaching this stage (Bittencourt et al. 2003; Bittencourt and Semir 2005; Gandolphi and Bittencourt 2010). Therefore, post-zygotic development of the new diploid sporophytic generation resulting from syngamy in ovules of selfed pistils in self-sterile Bignoniaceae seems to be restricted to zygote elongation and the following formation of a twonucleate proembryonal tube. Finally, embryogenesis apparently does not occur in purely self-pollinated pistils of self-sterile species of Bignoniaceae, which strongly undermines the possible involvement of early-acting recessive alleles as a cause of its self pistil abscission.

Acknowledgements I am grateful to the Fundação de Amparo à Pesquisa do Estado de São Paulo (Process number 2005/59234-4) for financial support. My thanks to Dr. William E. Friedman and staff at the Department of Ecology and Evolutionary Biology, University of Colorado at Boulder (USA), for permission to use the equipment and for help with microspectrofluoromety procedures, and to the two anonymous reviewers for critical reading of the manuscript and valuable suggestions.

\section{References}

Ayres M, Ayres M Jr, Ayres DL, Santos AS (2000) BioEstat 2.0. Aplicações estatísticas nas áreas das ciências biológicas e médicas. Sociedade Civil Mamirauá, Belém

Batygina TB, Vasilyeva VE (2001) In vivo fertilization. In: Bhojwani SS, Soh WY (eds) Current trends in embryology of angiosperms. Kluwer Academic Publishers, Dordrecht, pp 101-142

Batygina TB, Vinogradova GY (2007) Phenomenon of polyembryony. Genetic heterogeneity of seeds. Russ J Dev Biol 38:126-151. doi:10.1134/S1062360407030022

Bertin R, Barnes C, Guttman SI (1989) Self-sterility and cryptic selffertility in Campsis radicans (Bignoniaceae). Bot Gaz 150:397-403

Bittencourt NS Jr, Moraes CIG (2010) Self-fertility and polyembryony in South American yellow trumpet trees (Handroanthus chrysotrichus and $H$. ochraceus, Bignoniaceae): a histological study of postpollination events. Plant Syst Evol 288:59-76. doi:10.1007/s00606-010-0313-2
Bittencourt NS Jr, Semir J (2004) Pollination biology and breeding system of Zeyheria montana (Bignoniaceae). Plant Syst Evol 247:241-254. doi:10.1007/s00606-004-0142-2

Bittencourt NS Jr, Semir J (2005) Late-acting self-incompatibility and other breeding systems in Tabebuia (Bignoniaceae). Int J Plant Sci 166:493-506. doi:10.1086/428758

Bittencourt NS Jr, Semir J (2006) Floral biology and late-acting selfincompatibility in Jacaranda racemosa (Bignoniaceae). Aust $\mathbf{J}$ Bot 54:315-324. doi:10.1071/BT04221

Bittencourt NS Jr, Gibbs PE, Semir J (2003) Histological study of post-pollination events in Spathodea campanulata Beauv. (Bignoniaceae), a species with late-acting self-incompatibility. Ann Bot-Lond 91:827-834. doi:10.1093/aob/mcg088

Bittencourt NS Jr, Pereira EJ Jr, São-Thiago PS, Semir J (2011) The reproductive biology of Cybistax antisyphilitica (Bignoniaceae), a characteristic tree of the South American savannah-like "Cerrado" vegetation. Flora 206:872-886. doi:10.1016/j.flora. 2011.05.004

Bullock SH (1985) Breeding systems in the flora of a tropical deciduous forest in Mexico. Biotropica 17:287-301

Burbidge AH, James SH (1991) Postzygotic seed abortion in the genetic system of Stylidium (Angiospermae: Stylidiaceae). J Hered 82:319-328

Carmichael JS, Friedman WE (1995) Double fertilization in Gnetum gnemon: the relationship between the cell cycle and sexual reproduction. Plant Cell 7:1975-1988. doi:10.1105/tpc.7.12. 1975

Cope FW (1962) The mechanism of pollen incompatibility in Theobroma cacao L. Heredity 17:157-182. doi:10.1038/hdy. 1962.14

Costa ME, Sampaio DS, Paoli AAS, Leite SCAL (2004) Poliembrionia e aspectos da embriogênese em Tabebuia ochracea (Chamisso) Standley (Bignoniaceae). Rev Bras Bot 27:395-406. doi:10.1590/S0100-84042004000200017

Davis GL (1966) Systematic embryology of the angiosperms. John Wiley \& Sons, New York

Friedman WE (1991) Double fertilization in Ephedra trifurca, a nonflowering plant: the relationship between fertilization events and the cell cycle. Protoplasma 165:106-120. doi:10.1007/ BF01322281

Friedman WE (1999) Expression of the cell cycle in sperm of Arabidopsis: implications for understanding patterns of gametogenesis and fertilization in plants and other eukaryotes. Development 126:1065-1075

Gandolphi G, Bittencourt NS Jr (2010) Sistema reprodutivo do ipêbranco-Tabebuia roseo-alba (Ridlay) Sandwith (Bignoniaceae). Acta Bot Bras 24:840-851. doi:10.1590/S010233062010000300026

Gentry AH (1992) Bignoniaceae-part II (Tribe Tecomeae). Flora Neotropica, monograph 25(II). The New York Botanical Garden, New York

Gerassimova-Navashina H (1960) A contribution to the cytology of fertilization in flowering plants. Nucleus 3:111-120

Gibbs PE (2014) Late-acting self-incompatibility-the pariah breeding system in flowering plants. New Phytol 203:717-734. doi:10. 1111/nph.12874

Gibbs PE, Bianchi MB (1999) Does late-acting self-incompatibility (LSI) show family clustering? Two more species of Bignoniaceae with LSI: Dolichandra cynanchoides and Tabebuia nodosa. Ann Bot-Lond 84:447-457. doi:10.1006/anbo.1999. 0933

Gibbs PE, Bianchi MB, Taroda Ranga N (2004) Effects of self-, chase and mixed self/cross-pollinations on pistil longevity and fruit set in Ceiba species (Bombacaceae) with late-acting self-incompatibility. Ann Bot-Lond 94:305-310. doi:10.1093/aob/mch141 
Govindu HC (1950) Studies in the embryology of some members of Bignoniaceae. Proc Indian Acad Sci B 32:164-178

Hao Y-Q, Zhao X-F, She D-Y, Xu B, Zhang D-Y, Liao W-J (2012) The role of late-acting self-incompatibility and early-acting inbreeding depression in governing female fertility in monkshood, Aconitum kusnezoffii. PLOS ONE 7:e47034. doi:10.1371/ journal.pone.0047034

Husband BC, Schemske DW (1996) Evolution of the magnitude and timing of inbreeding depression in plants. Evolution 50:54-70. doi: $10.2307 / 2410780$

Johri BM, Ambegaokar KB, Srivastava PS (1992a) Comparative embryology of angiosperms, vol I. Springer, Berlin

Johri BM, Ambegaokar KB, Srivastava PS (1992b) Comparative embryology of angiosperms, vol II. Springer, Berlin

Klekowski EJ (1988) Mutation, developmental selection, and plant evolution. Coilumbia University Press, New York

Konyar ST (2014) Ultrastructure of microsporogenesis and microgametogenesis in Campsis radicans (L.) Seem. (Bignoniaceae). Plant Syst Evol 300:303-320. doi:10.1007/s00606-013-0883-x

LaDoux T, Friar EA (2006) Late-acting self-incompatibility in Ipomopsis tenuifolia (Gray) V. Grant (Polemoniaceae). Int J Plant Sci 167:463-471. doi:10.1086/500985

Lipow SR, Wyatt R (2000) Single gene control of postzygotic selfincompatibility in poke milkweed, Asclepias exaltata L. Genetics 154:893-907

Meinke DW (1991) Perspectives on genetic analysis of plant embryogenesis. Plant Cell 3:857-866. doi:10.1105/tpc.3.9.857

Milet-Pinheiro P, Carvalho AT, Kevan PG, Schlindwein C (2009) Permanent stigma closure in Bignoniaceae: mechanisms and implications for fruit set in self-incompatible species. Flora 204:82-88. doi:10.1016/j.flora.2007.11.006

Mogensen HL, Holm PB (1995) Dynamics of nuclear DNA quantities during zygote development in barley. Plant Cell 7:487-494. doi:10.1105/tpc.7.4.487

Mogensen HL, Leduc N, Matthys-Rochon E, Dumas C (1995) Nuclear DNA amounts in the egg and zygote of maize (Zea mays L.). Planta 197:641-645. doi:10.1007/BF00191572

Natesh S, Rau MA (1984) The embryo. In: Johri BM (ed) Embryology of angiosperms. Springer, Berlin, pp 377-443

O'Brien TP, Feder N, McCully ME (1964) Polychromatic staining of plant cell walls by toluidine blue O. Protoplasma 59:367-373 . doi:10.1007/BF01248568

Olmstead RG, Zjhra ML, Lohmann LG, Grose SO, Eckert AJ (2009) A molecular phylogeny and classification of Bignoniaceae. Am J Bot 96:1731-1743. doi:10.3732/ajb.0900004

Raghavan V (2003) Some reflections on double fertilization, from its discovery to the present. New Phytol 159:565-583. doi:10.1046/ j.1469-8137.2003.00846.x

Sage TL, Bertin R, Williams EG (1994) Ovarian and other late-acting self-incompatibility. In: Williams EG, Clark AE, Knox RB (eds)
Genetic control of self-incompatibility and reproductive development in flowering plants, vol 2. Kluwer, Dordrecht, pp 116-140

Sampaio DS, Bittencourt NS Jr, Oliveira PE (2013) Sporophytic apomixis in polyploid Anemopaegma species (Bignoniaceae) from central Brazil. Bot J Linn Soc 173:77-91. doi:10.1111/boj. 12076

Sampaio DS, Mendes-Rodrigues C, Engel TBJ, Rezende TM, Bittencourt NS Jr, Oliveira PE (2016) Pollination biology and breeding system of syntopic Adenocalymma nodosum and $A$. peregrinum (Bignonieae, Bignoniaceae) in the Brazilian savanna. Flora 223:19-29. doi:10.1016/j.flora.2016.04.009

Schlindwein C, Westerkamp C, Carvalho AT, Milet-Pinheiro P (2014) Visual signaling of nectar-offering flowers and specific morphological traits favour robust bee pollinators in the massflowering tree Handroanthus impetiginosus (Bignoniaceae). Bot J Linn Soc 176:396-407. doi:10.1111/boj.12212

Seavey SR, Bawa KS (1986) Late-acting self-incompatibility in angiosperms. Bot Rev 52:195-219. doi:10.1007/BF02861001

Seavey SR, Carter SK (1994) Self-sterility in Epilobium obcordatum (Onagraceae). Am J Bot 81:331-338

Shivaramiah G (1998) Endosperm development in Bignoniaceae. Phytomorphology 48:45-50

Stevens AD (1994) Reproduktionsbiologie einiger Bignoniaceen in Cerrado brasiliens. Biosystematics and ecology series 5. Österreichische Akademie der Wissenschaften, Wien

Tian RQ, Yuan T, Russell SD (2005) Relationship between double fertilization and the cell cycle in male and female gametes of tobacco. Sex Plant Reprod 17:243-252. doi:10.1007/s00497004-0233-9

Valtueña FJ, Rodríguez-Riaño T, Espinosa F, Ortega-Olivencia A (2010) Self-sterility in two Cytisus species (Leguminosae, Papilionoideae) due to early-acting inbreeding depression. Am J Bot 97:123-135. doi:10.3732/ajb.0800332

van Went JL, Willemse MTM (1984) Fertilization. In: Johri BM (ed) Embryology of angiosperms. Springer, Berlin, pp 273-317

Wiens D, Calvin CL, Wilson CA, Davern CI, Frank D, Seavey SR (1987) Reproductive success, spontaneous embryo abortion, and genetic load in flowering plants. Oecologia 71:501-509. doi:10. 1007/BF00379288

Willemse MTM, van Went JL (1984) The female gametophyte. In: Johri BM (ed) Embryology of angiosperms. Springer, Berlin, pp 159-196

Williams JH, Friedman WE (2002) Identification of diploid endosperm in an early angiosperm lineage. Nature 415:522-526. doi:10.1038/415522a

Woodard JW (1956) DNA in gametogenesis and embryogeny in Tradescantia. J Biophys Biochem Cytol 2:765-776

Zar JH (1999) Biostatistical analysis. Prentice-Hall, New Jersey 